\title{
Development of an action plan to implement the global strategy to reduce harmful use of alcohol in the Eastern Mediterranean Region ${ }^{1}$
}

Citation: Development of an action plan to implement the global strategy to reduce harmful use of alcohol in the Eastern Mediterranean Region. East Mediterr Health J. 2021;27(12):1239-1240. https://doi.org/10.26719/emhj.21.076

Copyright (c) World Health Organization (WHO) 2021. Open Access. Some rights reserved. This work is available under the CC BY-NC-SA 3.o IGO license (https://creativecommons.org/licenses/by-nc-sa/3.o/igo).

Alcohol use is associated with many social and health consequences, including liver disease, cardiovascular disease, cancer, tuberculosis, HIV/AIDS, road traffic accidents, rape, violence, suicide, as well as mental, neurological and substance use disorders (1). Alcohol consumption among adult population (aged 15 years and above) in the Eastern Mediterranean Region is estimated to be 0.6 litres of pure alcohol per capita per year, lower than the global average of 6.0 litres of pure alcohol per capita per year $(2,3)$. Reports have shown that $70.5 \%$ of alcohol consumption in the region is not documented in national statistics on alcohol taxation or sales because it is mostly produced and sold outside official channels (4). Information about treatment is limited as most countries in the region do not have specialized treatment services for alcohol use disorders and dependence.

In response to a request by its Executive Board for accelerated action to reduce the harmful use of alcohol, the WHO Secretariat initiated a process for the development of an action plan. Beginning with a technical meeting in June 2020, WHO facilitated technical consultations with Member States of the Eastern Mediterranean Region to develop an action plan for 2022-2030, based on a working document developed for this purpose. Representatives of 18 countries and territories in the Region ${ }^{2}$, including the ministries of health, academic institutions, WHO collaborating centres, and staff of the WHO country offices, regional office and headquarters participated in the consultations.

The objectives of the consultations were to receive input from participants for the first draft of the action plan to accelerate action on implementation of the global strategy to reduce harmful use of alcohol as a public health priority $(1,5)$; and to strengthen regional networking for implementation of the action plan.

\section{Summary of discussions}

Participants acknowledged that problems with harmful use of alcohol exist in all countries of the region, even in countries with the most restrictive legislations. They agreed that the action plan is relevant to all countries and offers a wide range of policy options and interventions that Member States can adopt. They however noted that implementation of some of the proposed actions would be challenging (3), as some countries in the region do not want to include alcohol modules in their populationbased surveys and data collection tools.

Limited data is available about alcohol use and its harmful effects in the region, there is, therefore, a need for research to generate region-specific information on alcohol use, including estimates on alcohol consumption, alcohol-related harms, and policy responses, as indicated in the WHO monitoring frameworks. Increasing technical support and strengthening capacity in this area is a priority, particularly prevention and treatment programmes and establishment of treatment facilities for alcohol use disorders within the broader health packages.

Participants emphasized the need for effective advocacy, awareness and partnerships as well as commitment and coordination by health authorities. These measures could be boosted by activating or reviving the global and regional networks and strengthening intersectoral collaboration between ministries of health and other sectors such as the media and ministries of education, finance and interior.

The meeting noted the need for an action plan to address the needs of special populations such as young people, women, migrants, refugees, and internally displaced people as well as gender and equity issues, using community-based approaches. To facilitate advocacy for resource mobilization, participants recommended the development of investment cases for alcohol, specifically under the SAFER global initiative (6).

Participants endorsed the global targets and the proposed actions for Member States, the WHO Secretariat, international partners, and non-state actors in all the six action areas presented in the working document, including implementation of high-impact strategies and interventions; advocacy, awareness and commitment; partnership, dialogue and coordination; technical support and capacity-building; knowledge production and information systems; and resource mobilization.

\section{Recommendations}

Member States are to consider the outcomes of the regional technical consultations when developing their country positions on the draft global action plan for the next stages of the consultation. They will continue

\footnotetext{
This summary was extracted from the report of the regional technical consultation on the working document for development of the action plan (2022-2030) to effectively implement the global strategy to reduce the harmful use of alcohol as a public health priority, https://applications.emro.who.int/docs/WHOEMMNH227E-eng.pdf?ua=1.

${ }^{2}$ Afghanistan, Bahrain, Egypt, Iran (Islamic Republic of), Iraq, Jordan, Kuwait, Lebanon, Libya, Morocco, occupied Palestinian territory, Pakistan, Qatar, Somalia, Syrian Arab Republic, Tunisia, United Arab Emirates, and Yemen.
} 
to support the development of the action plan and facilitate nomination of members to the regional network, which is expected to actively participate in the development and implementation of the plan. Participants requested WHO to finalize the list of targets and their related indicators, complete the definitions for the proposed indicators, and share the draft document with individuals who participated in the consultations for final comments.

\section{References}

1. World Health Organization, 2018. Alcohol, 21 September. Geneva: https://www.who.int/news-room/fact-sheets/detail/alcohol.

2. World Health Organization, 2018. Global status report on alcohol and health 2018: executive summary. Geneva: https://apps. who.int/iris/bitstream/handle/10665/312318/WHO-MSD-MSB-18.2-eng.pdf.

3. Manthey J, Shield K, Rylett M, Hasan O, Probst C, \& Rehn J, 2019. Global alcohol exposure between 1990 and 2017 and forecasts until 2030: a modelling study. The Lancet, 393 (10190): 2493-2502, DOI: https://doi.org/10.1016/So140-6736(18)32744-2.

4. Flor LS \& Gakidou E, 2020. The burden of alcohol use: better data and strong policies towards a sustainable development. The Lancet, 5(1): E10-E11, DOI: https://doi.org/10.1016/S2468-2667(19)30254-3.

5. World Health Organization, 2005. Public-health problems caused by harmful use of alcohol. Resolutions and Decisions of the Fifty-eighth World Health Assembly, WHA58.26. Geneva: http://apps.who.int/iris/bitstream/handle/10665/20376/WHA58_26-en. pdf.

6. World Health Organization, 2018. The SAFER initiative: A world free from alcohol related harm. Geneva: https://www.who. int/initiatives/SAFER\#: :text=The\%20SAFER\%20initiative\%20A\%20world\%20free\%20from\%20alcohol,international\%20partners $\% 2$ C $\% 2$ olaunched $\% 20$ the $\% 20$ SAFER\%20initiative $\% 20$ in $\% 202018$. 